\title{
CRISE DO CAPITALISMO E EDUCAÇÃO: AS ESTRATÉGIAS SOCIAIS-LIBERAIS DE FOCALIZAÇÃO NA POBREZA DOS GOVERNOS "NEODESENVOLVIMENTISTAS"
}

\section{Kivania Karla Albuquerque Cunha ${ }^{1}$ \\ Larissa Martins Almeida ${ }^{2}$}

Resumo: O nosso artigo pretende discutir a estratégia engendrada pelo grande capital de focalização na extrema pobreza com vistas a atenuar os antagonismos de classe em tempos de globalização da "questão social". Para tanto, procura discutir o papel dado a política de educação neste contexto, trazendo ao debate os mecanismos sociais-liberais utilizados pelos governos "neodesenvolvimentistas" para direcionar os investimentos da educação em programas que promovam um investimento em capital humano através da educação básica e profissionalizante e do incentivo ao empreendedorismo.

Palavras-chave: Neoliberalismo; Social-liberalismo; Políticas Sociais; Educação. Pobreza.

${ }^{1}$ Programa de Pós-graduação em Serviço Social da Universidade Estadual da Paraíba, Brasil. Email: kivaniass@gmail.com.

2Programa de Pós-graduação em Serviço Social da Universidade Estadual da Paraíba, Brasil, Email: larissa_uepb@yahoo.com.br. 